\title{
The Process of Developing an Integrated Model of Catering Services Efficiency
}

\author{
Ph.D. Candidate İlhama İskandarova (Odlar Yurdu University, Azerbaijan)
}

\begin{abstract}
The rapid socio-economic development of the Republic of Azerbaijan is conditioned by many factors, including the sphere of services in various sectors of the economy, including the catering market.

In recent years, the catering market in the country has expanded significantly. During 2000-2015 alone, the catering turnover in the country increased from 18.4 million manat to 1111.2 million manat.

Such a pace of development of catering services has not been observed in any other sector of the economy. The growing role of the catering market in the country fully justifies the fact that the welfare of the country's workers has significantly increased, which is an important element in the integrated assessment of the development of society. To solve many complex problems of the catering market, we need a scientific basis based on modern research methods, including complex marketing research.

In addition, in order to solve a large number of such complex problems, it is necessary to pay special attention to regulatory issues, reducing the level of production costs, rapid development of market infrastructure, raising the level of service culture. Ultimately, this will ensure that tactics and strategies improve the performance of market services in line with market conditions. We believe that a scientific approach to complex marketing research will help solve many problems in the catering market.
\end{abstract}

\section{Introduction}

The final stage of complex marketing research should be the process of developing an integrated model of marketing effectiveness.

To this end, it is necessary to develop a concept for evaluating marketing activities. It represents an integrated model that describes the effectiveness of marketing in a firm as a constant dynamic process. The model expresses the process of the sequence of efficiency, built on the principle of cause-and-effect relationships, that is, each step that comes before is the basis for the next step.

We believe that the final stage of complex marketing research should be the process of developing an integrated model of marketing effectiveness.

\section{Methodology}

For this purpose, it is necessary to develop a concept for evaluating marketing activities. This represents an integrated model that describes the effectiveness of marketing in a firm as a constant dynamic process (Arsenyeva E.V., Nosova G.V., 2015).

The model expresses the process of the sequence of efficiency, built on the principle of cause-and-effect relationships, that is, each step that comes before is the basis for the next step.

The peculiarity of the development of an integrated model for assessing the effectiveness of catering services marketing is that it is necessary to reflect the specifics of efficiency in the field of catering services. We believe that this model can be described as follows in the example of the expansion of the restaurant "Fontan" (Alekseev A.N., 2014). 


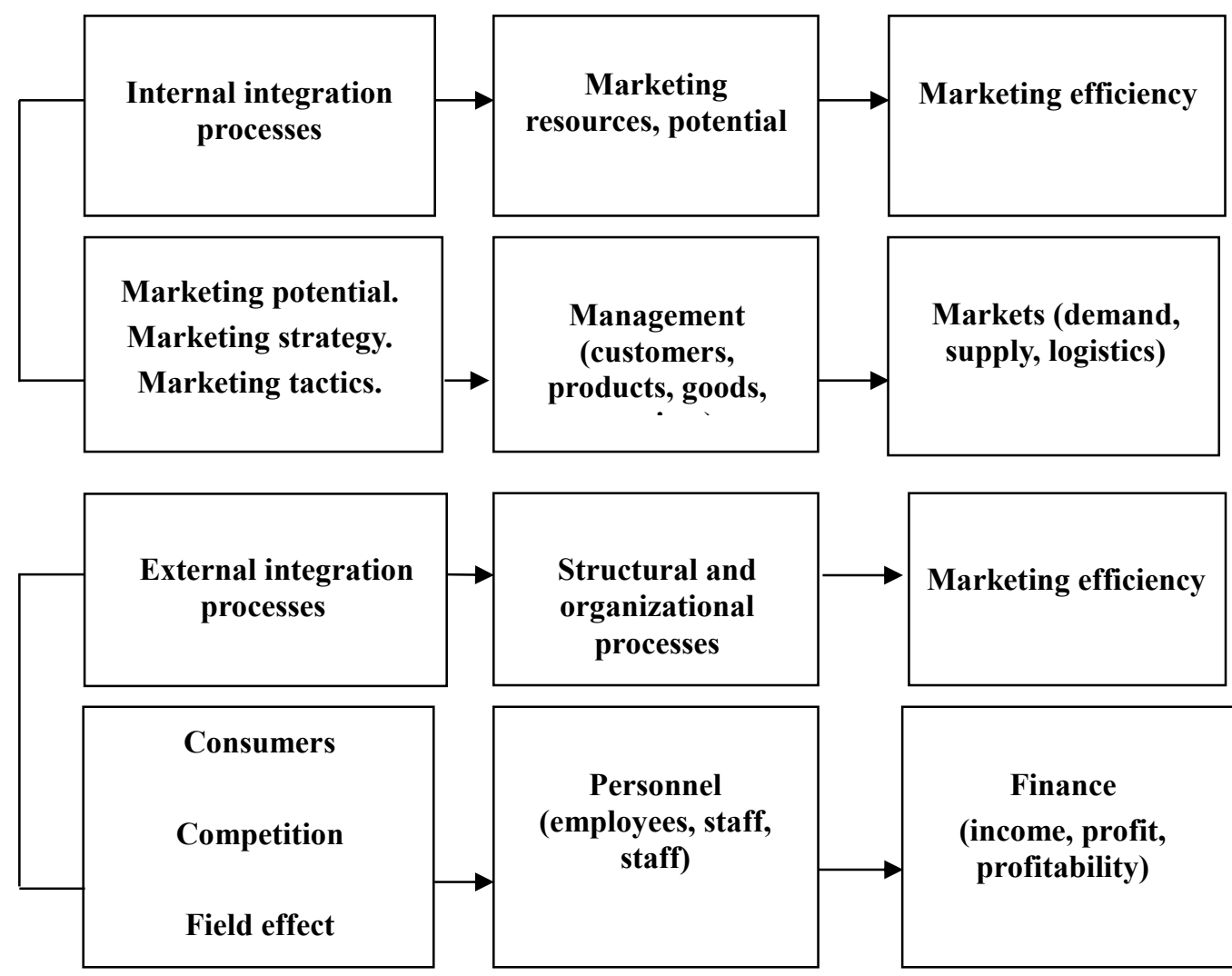

Figure 1. Integrated Model for Evaluating the Effectiveness of Service Marketing in the Restaurant

As can be seen, the proposed integrated model for assessing the effectiveness of catering services marketing in the RN Fontan restaurant consists of two blocks (Gashimov G.I., 2015).

1. Internal integrated processes, including marketing potential, marketing strategy, marketing tactics. The subblocks of this model are marketing resources (management - customers, products, goods, services) and marketing efficiency (market - raw materials, supply, logistics).

2. Externally integrated processes, including customers, competitiveness, industry impact. The sub-blocks of this model are structural and organizational processes (personnel - employees, employees, personnel) and marketing efficiency (finance - income, profit, profitability) (Kotler F., 2016).

The proposed integrated model of efficiency shows that there is a connection between the sphere of marketing and the sphere of service delivery, and managers in both spheres should try to understand the goals of the other party.

At the same time, marketers need to understand that the majority of contacts are related to the interaction between the customer and the staff, which highlights the importance of human resource management, especially in service areas with a high level of contacts.

The final practical result of the marketing function of the provision of services in the field of market relations, and ultimately the operation of the whole system, is the fulfillment of a specific goal determined by the needs of the consumer. Our research has shown that the specific model of activity and work of a particular enterprise as a result of market relations is the result of the introduction of a certain generalized logistics model of the market. All this allows us to characterize the interaction of the main elements of the service marketing system and reveal their regularities.

When integrating all the subsystems that determine customer satisfaction activities into the model, it should be noted that only a certain balance of all interrelated elements allows the catering company to operate optimally in the services market. The operation of such a system, by its very nature, does not require the administration of a traditional administrative command. The system is self-regulating, its operation depends primarily on the balance of demand and consumption of services. Conceptually, the integration of the catering enterprise into the system of market relations means the replacement of the management system of the enterprise with the original system of self-regulatory marketing activities to meet the target needs of the customer for a particular service.

The interaction of all the components of the characteristics of this activity in the market system is a reflection of certain complex relationships inherent in the market of services. 


\section{Results}

The developed model is, by its nature, universal for market structures, which allows it to be used not only in the context of services, but also in other areas of production and commercial activities related to marketing relations. At the present stage:

- search and describe the relevant relationships of the elements used in the services marketing system;

- identify and substantiate the functional dependence of the elements of the service marketing model, logically describe these dependencies using modern methods;

- it is important to build and develop situational models of systematic and integrated levels.

Thus, in general, the considered functional elements can be divided into two groups.

The first group includes elements that characterize the subjects (consumers and producers) and objects of the marketing system: external environmental factor, product image, standard, economic group, consumer group, professional group, purchasing power, purchasing power, wages, product value, service status, labor evaluation, unit of goods, unit of labor, efficiency.

The second group includes the elements (need, demand, supply, welfare, bargaining, training, demand, activity, satisfaction) that characterize the certain situation and movement of the subjects of the system against the background of market relations.

Thus, the integrated model of service marketing expresses the logical regularity-universal connection of the elements and concepts that characterize human activity aimed at meeting the needs and requirements through exchange.

\section{Conclusions}

The integrated model of service marketing efficiency in modern conditions solves systemic strategic issues consisting of four stages.

Strategy I - "capturing depth in the market", can be used when the market and its consumers are known. It is not difficult to identify the segments. In this case, a selective approach involving the selection of one or more wellknown segments is appropriate. This strategy is applied when a new phase of the standard format already exists in the market, and you have to base your "depth" on your own concept.

Strategy II - focuses on the largest number of possible segments, selected on the basis of careful analysis of the firm's resources and customer segments.

Strategy III - refers to the specialization of the catering company. This approach is close to the first strategy, the only difference being that the proposal is not very specific. For example, the restaurant "Fontan" attracts the attention of a certain segment of customers with its appropriate environment, along with which everyone can get acquainted with a new type of fast food company.

Strategy IV - Differentiation of proposals is aimed at extensive expansion of activities and is justified when it is very difficult to identify segments. Using this strategy, it is necessary to determine the approximate boundaries of the segments, try to offer the maximum number of services and opportunities for such customers in your restaurant.

Finally, the most profitable concept for a catering company to ensure a competitive position in the market is to have any quality (kitchen, service, environment, interior) that is of great importance in the field. Having one of these qualities means working effectively. The competitive position of the restaurant on various criteria:

- on the basis of what customers prefer (restaurant for customers of fast food);

- based on traditions;

- for national cuisine;

- can be provided based on the popularity of the restaurant concept.

\section{References}

- Arsenyeva E.V., Nosova G.V. Marketing research. Moskow ,.MSU.2015, -441p.

- Alekseev A.N. Marketing services market research. Moscow, 2014,- 230 p.

- Gashimov G.I. Commercial activities in the service sector. Baku.AzDIU. 2015,-308p.

- Kotler.F. The basics of marketing. Moskow, 2016, - 752 c. 